\title{
Multiple nodular pulmonary amyloidosis
}

\author{
A case report and comparison with \\ diffuse alveolar-septal pulmonary amyloidosis
}

\author{
SIONG-CHUAN LEE and HORTON A. JOHNSON \\ Department of Pathology, Indiana University School of Medicine, $1100 \mathrm{~W}$. Michigan Street, \\ Indianapolis, Indiana 46202, USA
}

\begin{abstract}
Lee, S-C. and Johnson, H. A. (1975). Thorax, 30, 178-185. Multiple nodular pulmonary amyloidosis. A case of multiple nodular pulmonary amyloidosis in a 54-year-old Caucasian man is presented. Discrete symptomless radiodensities had developed in this patient's lungs within a period of three years, leading to a suspicion of a neoplastic process. The amyloid nature of these nodules was demonstrated by biopsy. In this case, as in others previously reported, there was no evidence of systemic disease, and immunoglobulins were normal. Local factors probably play an important part in the pathogenesis of this disease.

This entity is to be distinguished from the diffuse type of pulmonary amyloidosis, which has a far graver prognosis. Diffuse alveolar septal amyloidosis is usually associated with primary systemic amyloidosis or multiple myeloma and leads rapidly to respiratory distress.
\end{abstract}

Amyloidosis, either generalized or localized, can affect the upper or lower respiratory tract. Amyloidosis of the larynx, trachea, and bronchi is well known and has been the subject of many reports (Whitwell, 1953; Prowse, 1958; Heiner, 1968; McGurk, 1968; Spencer, 1968; Attwood, Price, and Riddell, 1972). Amyloidosis of the lung parenchyma occurs in two different forms, the nodular type and the diffuse alveolar septal type. Although postmortem examinations frequently reveal small foci of amyloid in lung parenchyma which are of no clinical significance, amyloidosis can occasionally form single or multiple nodules or a diffuse pulmonary infiltrate that will draw special attention and will require medical management. Thus far, about 30 to 40 cases of isolated multiple or solitary nodular pulmonary amyloidosis (Whitwell, 1953; Prowse, 1958; Duke, 1959; Condon, Pinkham, and Hames, 1964; Cotton and Jackson, 1964; Fors and Ryden, 1964; Firestone and Joison, 1966; Hayes and Bernhardt, 1969; Zundel and Prior, 1971; Dyke et al., 1974) and less than 15 cases of diffuse alveolar septal amyloidosis (Larsen, 1930; Sappington, Davie, and Horneff, 1942; Bruno and Ober, 1968; Thomsen, 1968; Gonzalez-Cueto et al., 1970; Crosbie et al., 1972) have been reported in the literature. The following is a report of a case of isolated multinodular pulmonary amyloidosiş which was investigated at Indiana University Medical Center following discovery by routine chest radiography. This case is reported not only because of the rarity of the condition, but als $\Phi$ because of its striking difference from the diffuse alveolar septal type of pulmonary amyloidosis iô its clinical aspects, prognosis, and histopathologi cal picture.

\section{CASE REPORT}

CLINICAL FINDINGS A 54-year-old Caucasian mat was admitted to Indiana University Medicant Center because of a chest radiograph which showed multiple nodular lesions in both lung fields strongly suggestive of neoplasm (Figs 3 and 4). The patient had been in good health except for mild gout, hypertension, and chronic intero mittent diarrhoea. Review of previous chest film§ showed the nodules to have been present, a though of smaller size, on 15 October 1971 (Fig.o 2 ), but entirely absent from a chest film take $\bar{P}$ on 3 October 1969 (Fig. 1). Physical examinatio was within normal limits, showing no evidenc $\Phi$ of respiratory distress, hepatosplenomegaly, of 


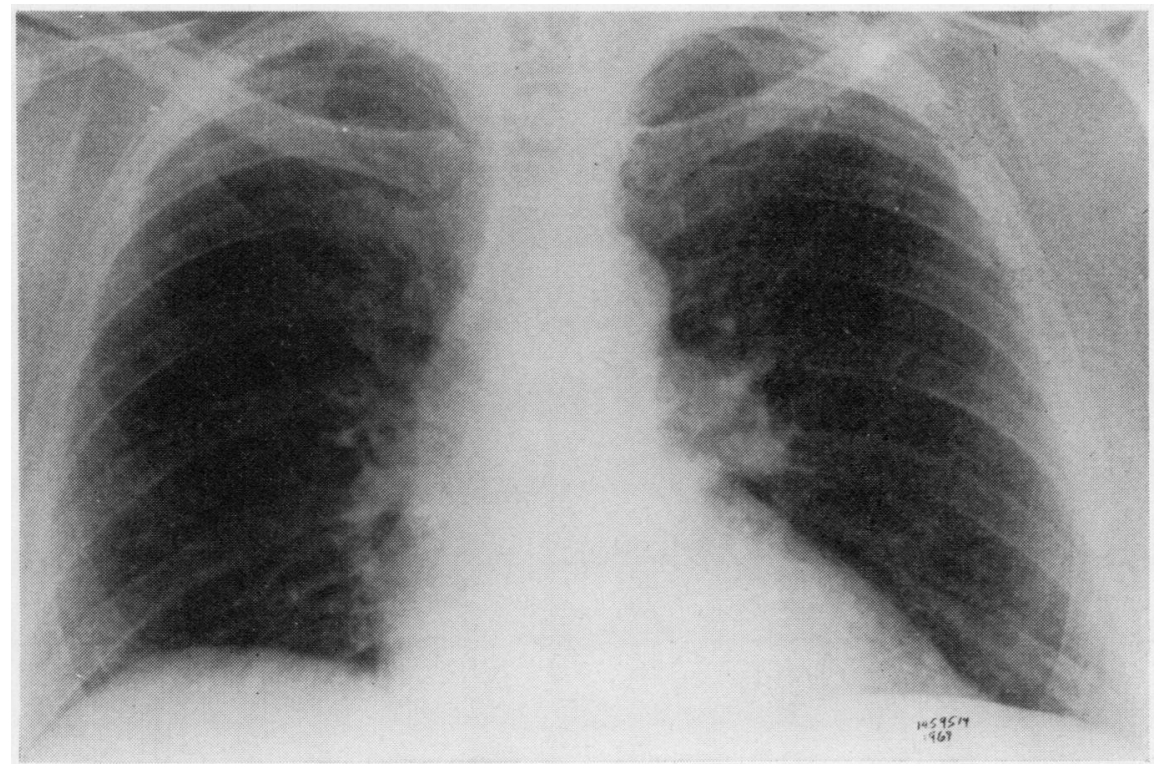

FIG. 1. Chest radiograph in 1969 showing no evidence of nodular lesions.

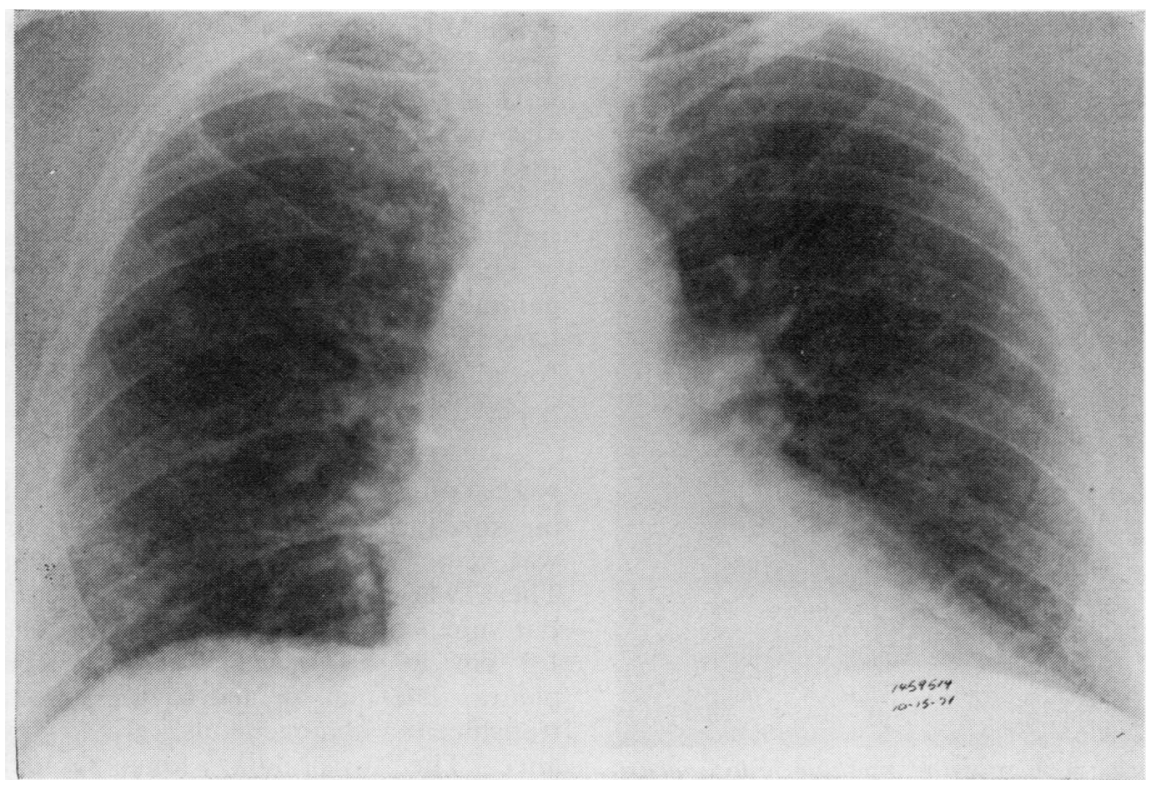

FIG. 2. Chest radiograph in 1971 showing multiple nodular lesions in both lung fields. 


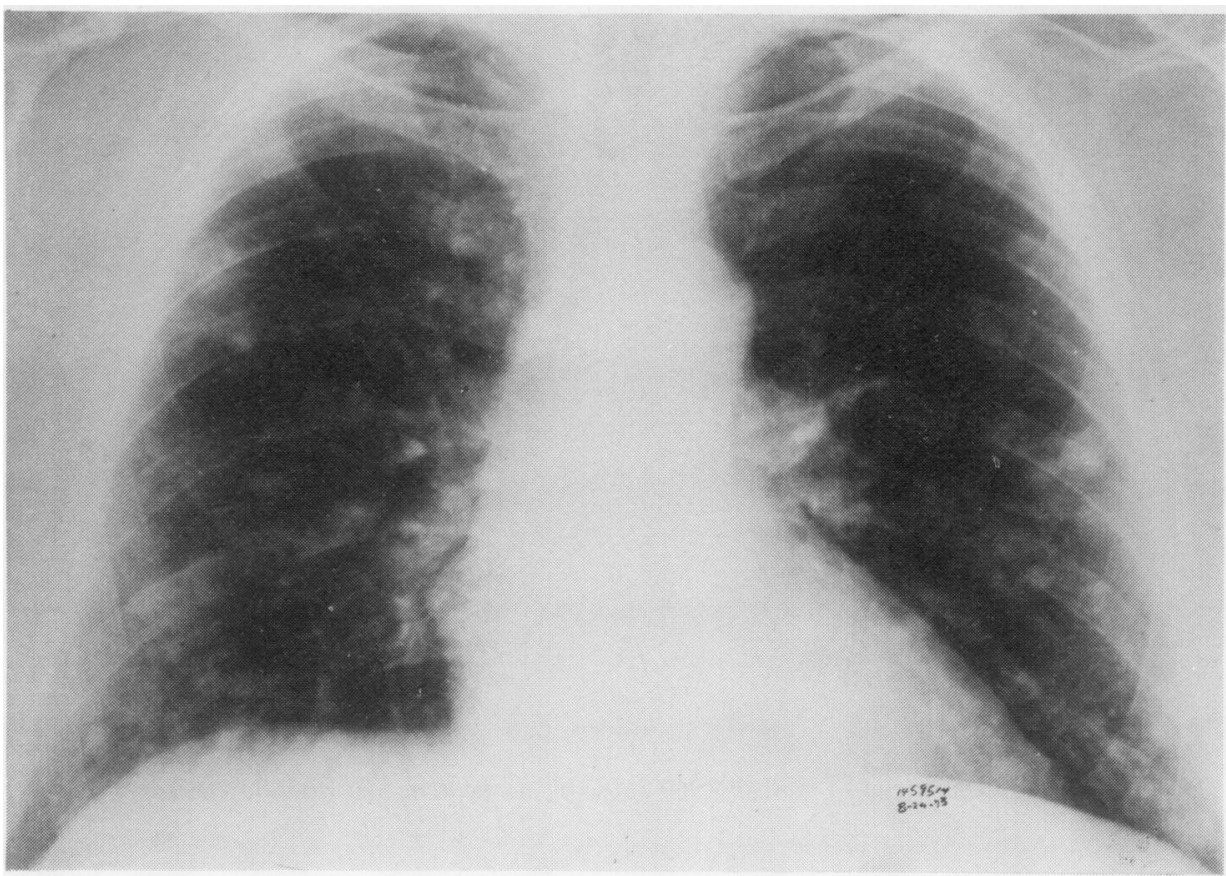

FIG. 3. Chest radiograph in 1973 before exploratory thoracotomy showing increase in size and density of the nodular lesion in both lung fields.

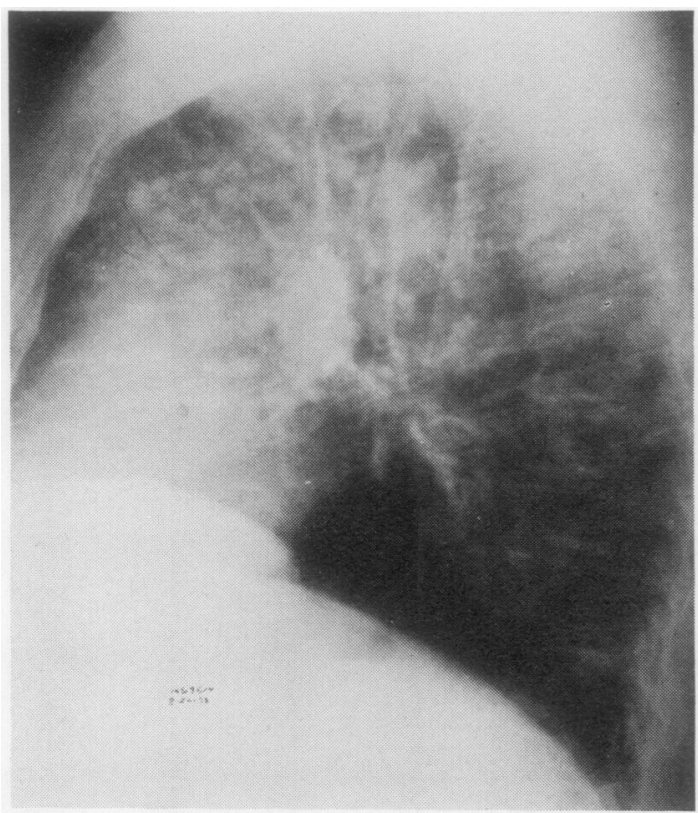

FIG. 4. Lateral view showing nodular lesions distributed in the anterior and posterior parts of the lungs. macroglossia. Diagnostic tests, including creatinine clearance, liver function tests, pul monary function tests, intravenous pyelography and liver and spleen scans, were also within normal limits. The bone marrow examination showed no evidence of multiple myeloma or othe neoplastic disease. No Bence-Jones protein waş. present in the urine. Serum electrophoresis and? immunodiffusion studies showed normal immuno globulins with no evidence of a monoclonaB gammopathy. An exploratory thoracotomy was carried out, and multiple discrete nodules were. found in the subpleural areas. A representativg wedge biopsy was taken.

PATHOLOGICAL FINDINGS The surgical specimen measured $5 \times 5 \times 1.0 \mathrm{~cm}$. The pleural surface was smooth but elevated by underlying nodules? There were several discrete, well-circumscribed $\$$ but unencapsulated nodules measuring 0.5 to $1.0 \mathrm{~cm}$ in diameter immediately beneath the pleura. The cut surface of these nodules had ap translucent, homogeneous, gray, waxy appear $\frac{\text { ? }}{0}$ ance. The surrounding lung parenchyma was slightly compressed. On examination by lighe 
microscopy the nodules were well demarcated from the lung parenchyma (Fig. 5). Each mass was composed of amorphous, homogenous, eosinophilic material, which stained red to pink with Congo Red and metachromatically with Crystal Violet. Within the nodules foci of calcification and dystrophic bone formation were seen (Fig. 6). At the periphery of each nodule there were variable numbers of lymphocytes, plasma cells, histiocytes, and a few multinucleated giant cells (Fig. 7).

HOSPITAL COURSE The postoperative course was uneventful, and the patient was discharged in good condition without specific treatment. He has remained free of symptoms since that time.

\section{DISCUSSION}

Although isolated nodular pulmonary amyloidosis is a very rare type of localized amyloidosis, this entity was reported as early as 1877 by Lesser. Since then some 30 to 40 cases have appeared in the literature. Most of these cases have been tabulated and reviewed by Condon et al. (1964), Firestone and Joison (1966), Weiss (1960), and Fors and Ryden (1964), and so a further review of these cases is not necessary here. In brief, the disease tends to affect patients in an older age group. The average age of the 30 well-documented cases was 68 years. Two-thirds of those patients were over 60 , one-third were older than 70 , and the overall age range was 38 to 95 . No sex predilection has been noted. The majority of patients were free of symptoms, and pulmonary function tests have shown no evidence of impairment of gas transfer. These patients were generally discovered by routine chest radiographs which were interpreted as either metastatic neoplasm or miliary tuberculosis. The histopathology has been presented in detail by Weiss (1960). The most prominent features are the presence of amyloid, calcification, dystrophic bone formation with plasma cells, histiocytes, lymphocytes, and multinucleated giant cells. The intimate relationship between amyloid and plasma cells is well known, and it is thought that plasma cells play a role in the production and perhaps also in the degradation of immunoglobulins (Glenner, 1973). The role of the multinucleated giant cells, which are also present in the diffuse alveolar septal type of amyloidosis and in amyloid tumours of the larynx, is not clear, but they may represent a host reaction to abnormal protein. The common finding of calcification and ossification of these nodules indicates their long duration. In the cases on which necropsies have been carried out, none has shown amyloidosis of other visceral organs.

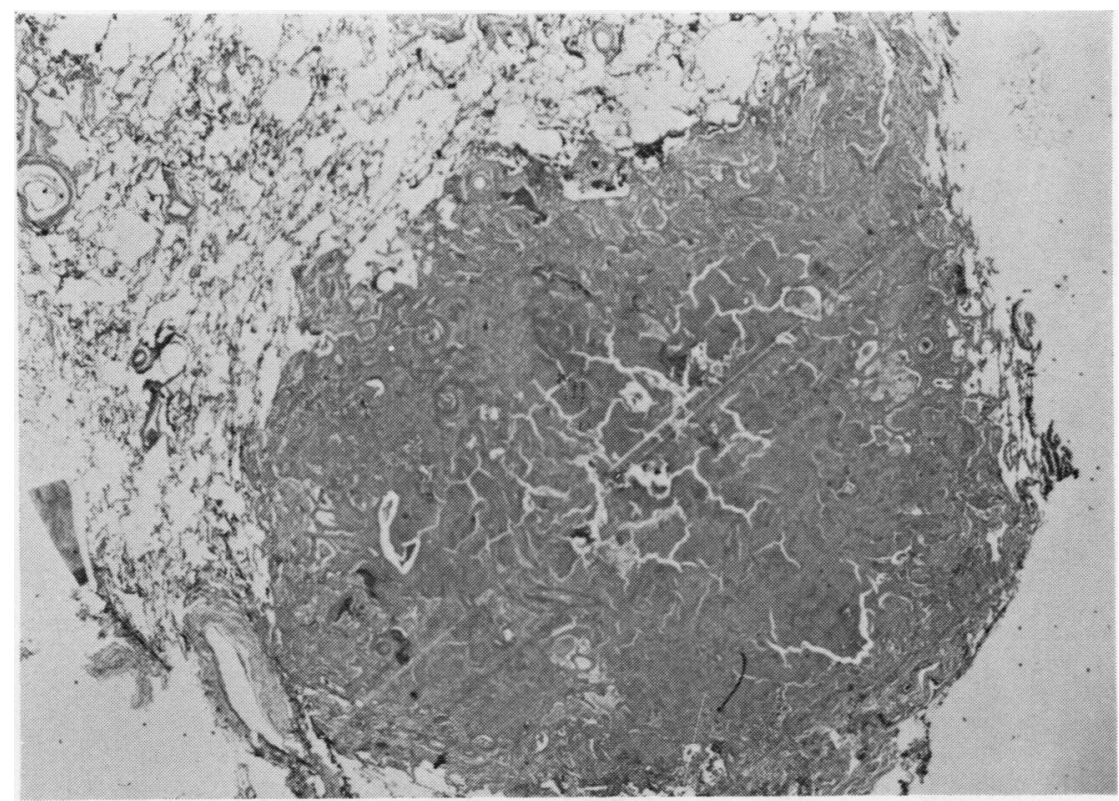

FIG. 5. Low magnification showing discrete well-demarcated amyloid nodule ( $H$ and $E \times 10)$. 


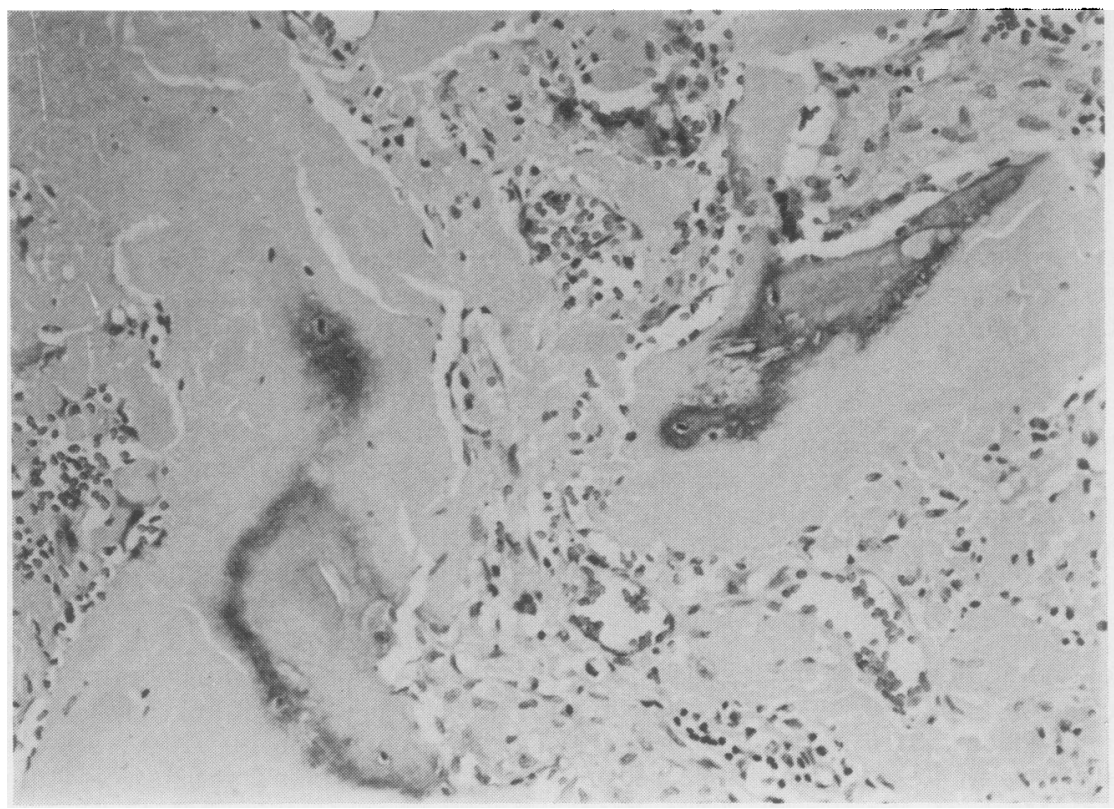

FIG. 6. Calcification and dystrophic bone formation within the amyloid nodule ( $H$ and $E \times 200$ ).

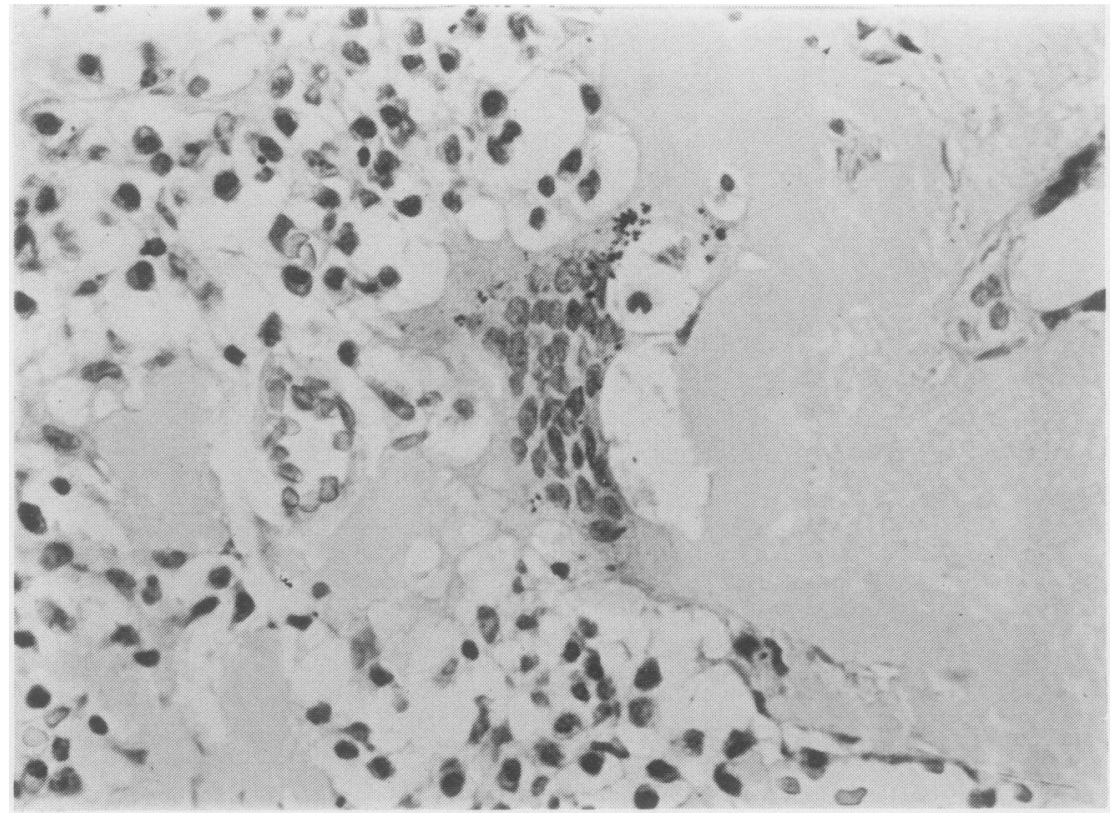

FIG. 7. Magnification showing close relationship of plasma cells and giant cell to the amyloid $(H$ and $E \times 400)$. 
In the present case, intensive investigation showed no evidence of extrapulmonary amyloidosis.

The isolated nodular type of amyloidosis is an entity quite distinct from the diffuse alveolar septal type of pulmonary amyloidosis. The latter is usually associated with overt multiple myeloma (Crosbie et al., 1972) or primary amyloidosis (Larsen, 1930; Sappington et al., 1942; Bruno and Ober, 1968; Thomsen, 1968), although a primary form without concurrent disease has also been reported by Zundel and Prior (1971) and Gonzalez-Cueto et al. (1970). The histological pattern of diffuse alveolar septal amyloidosis is entirely different from that of the isolated nodular type. The amyloid infiltration is diffuse, involving almost every alveolar septum. The amyloid is deposited around capillaries and within the interstitial tissue, ultimately obliterating alveolar capillaries. Grossly, the lungs are free of nodules but are bulky, rubbery, and heavy. There is apt to be a prominent inflammatory infiltrate similar to that found in the isolated nodular type. Patients usually die of respiratory insufficiency secondary to the extensive diffuse interstitial amyloid infiltrate.

The tinctorial characteristics of the amyloid are identical in both types of pulmonary amyloidosis, but the anatomical distribution of the amyloid leads to different clinical courses. The isolated nodular type is usually discovered incidentally and is nearly always misinterpreted as metastatic neoplasm or miliary tuberculosis, whereas the diffuse alveolar septal type is usually thought to be an inflammatory infiltrate or pulmonary oedema. In the present case, as in previously recorded cases, the amyloid infiltrate produced no signs or symptoms, whereas typically the patient with diffuse alveolar septal amyloidosis experiences severe respiratory difficulty with disturbed gas transfer. Isolated nodular amyloidosis, although untreated, has not led to death in any of the reported cases. On the other hand, patients with the diffuse type, as reported by Sappington et al. (1942), Crosbie et al. (1972) and Gonzalez-Cueto et al. (1970), all died of respiratory failure. Thus involvement of the lung by diffuse amyloidosis should always be suspected in a patient with multiple myeloma or primary generalized amyloidosis who develops respiratory insufficiency. The clinical differences between the isolated nodular pulmonary amyloidosis and the diffuse alveolar septal type are summarized in the Table.

The pathogenesis of amyloidosis is not well understood. The intimate relation between the
Bence-Jones protein and M-protein and amyloidosis has been emphasized by Osserman, Takatsuki, and Tatal (1964), Isobe and Osserman (1974), Glenner (1972, 1973), and Glenner, Ein, and Terry (1972), and the frequency of generalized amyloidosis in multiple myeloma has been reported to be as high as $20 \%$. Although amyloidosis in myeloma patients usually involves many visceral organs, the lung is nearly always spared. Twenty-seven well-documented cases with plasma-cell dyscrasia have been studied by Osserman et al. (1964), and none of the cases showed deposition of amyloid in the pulmonary parenchyma. However, once the lung is involved in multiple myeloma or primary amyloidosis, the clinical course is rapid and the patient dies of respiratory failure within a few months.

The general resistance of the lung to amyloidosis remains unexplained but may be due in part to the fact that the lung has considerable capacity for protein resorption, as evidenced by the rapid resorption of protein-rich oedema fluid. Since the presence of high levels of Bence-Jones protein or M-protein alone does not usually result in pulmonary amyloidosis, the occasional occurrence of pulmonary amyloidosis in multiple myeloma must depend also upon local factors in the lung, such as break-down of capillary integrity or

T A B L E

\begin{tabular}{|c|c|c|}
\hline & $\begin{array}{l}\text { Isolated Nodular } \\
\text { (Multiple or } \\
\text { Solitary) Pulmonary } \\
\text { Amyloidosis }\end{array}$ & $\begin{array}{c}\text { Diffuse } \\
\text { Alveolar-Septal } \\
\text { Pulmonary } \\
\text { Amyloidosis }\end{array}$ \\
\hline Associated diseases & None & $\begin{array}{l}\text { Multiple myeloma } \\
\text { Primary generalized } \\
\text { amyloidosis }\end{array}$ \\
\hline Chest radiograph & $\begin{array}{l}\text { Solitary or multiple } \\
\text { nodular lesions } \\
\text { simulating } \\
\text { metastatic or } \\
\text { primary neoplasm } \\
\text { in lung or miliary } \\
\text { tuberculosis }\end{array}$ & $\begin{array}{l}\text { Diffuse pulmonary } \\
\text { infiltrate resembling } \\
\text { pulmonary oedema } \\
\text { or inflammatory } \\
\text { infiltrate }\end{array}$ \\
\hline Lung function & Normal & Severely impaired \\
\hline $\begin{array}{l}\text { Impaired gas } \\
\text { transfer }\end{array}$ & Absent & Present \\
\hline $\begin{array}{l}\text { Bence-Jones protein } \\
\text { or M-protein }\end{array}$ & Undetectable & Always present \\
\hline Histopathology & $\begin{array}{l}\text { Multiple or solitary } \\
\text { discrete nodules }\end{array}$ & $\begin{array}{l}\text { Diffuse infiltration } \\
\text { of amyloid around } \\
\text { the capillaries and } \\
\text { within alveolar } \\
\text { septa }\end{array}$ \\
\hline Gross & $\begin{array}{l}\text { Slight increase in } \\
\text { weight or normal }\end{array}$ & $\begin{array}{l}\text { Bulky, rubbery, and } \\
\text { marked increase in } \\
\text { weight }\end{array}$ \\
\hline Course & Slow & Rapid \\
\hline Prognosis & Excellent & Poor \\
\hline
\end{tabular}


failure of adsorptive mechanisms. An out-pouring of abnormal proteins into the interstitial space, together with failure of resorption, may result in protein degradation and conversion to amyloid. Once amyloid is formed it cannot be reabsorbed.

It is possible that the production of isolated nodular amyloidosis of the lung may occur as a result of the same two factors, i.e., the presence of circulating amyloidogenic protein plus local factors, but that deposition occurs at a much lower rate because of the lower concentration of abnormal protein in the plasma. In fact, Glenner (1972) has isolated a portion of light chain protein from a case of nodular pulmonary amyloidosis, indicating that its pathogenesis is probably related to a primary disorder of the reticuloendothelial system.

At least one case of isolated nodular pulmonary amyloidosis has been associated with the macroglobulinaemia of Waldenstrom (Spencer, 1968). Although neither the present case nor previously reported cases have shown the presence of $\mathbf{M}$ protein or Bence-Jones protein, it is possible that the amount of abnormal protein in plasma is too small to be detected. It may also be the case that the amyloidogenic protein in these patients has been rapidly deposited in the lung so that the concentration in blood remains low. Thus it may be that both types of pulmonary amyloidosis have a similar pathogenesis and that the difference in clinical course and in anatomical distribution of amyloid depends chiefly upon the rate of deposition of amyloid which is in turn dependent upon the concentration of abnormal protein or amyloidogenic protein present in the blood stream of the affected patients.

\section{REFERENCES}

Attwood, H. D., Price, C. G., and Riddell, R. J. (1972). Primary diffuse tracheobronchial amyloidosis. Thorax, 27, 620.

Brigg, G. W. (1961). Amyloidosis. Annals of Internal Medicine, 55, 943.

Bruno, M. S. and Ober, W. B. (1968). Pleural effusion, dyspnea, and progressive liver enlargement. Clinicopathologic Conference of Beekman Downtown Hospital. New York State Journal of Medicine, 68, 1404.

Cathcart, E. S., Ritchie, R. F., Cohen, A. S., and Brandt, K. (1972). Immunoglobulins and amyloidosis. An immunologic study of sixty-two patients with biopsy-proved disease. The American Journal of Medicine, 52, 93.

Cohen, A. S. (1967). Amyloidosis. New England Journal of Medicine, 277, 522, 574, 628.
Condon, R. E., Pinkham, R. D., and Hames, G. H. (1964). Primary isolated nodular pulmonary? amyloidosis. Report of a case. Journal ofo Thoracic and Cardiovascular Surgery, 48, 498.

Cotton, R. E. and Jackson, J. W. (1964). Localized $\frac{\bar{\sigma}}{5}$ amyloid tumours of the lung simulating $\overparen{\odot}$ malignant neoplasms. Thorax, 19, 97.

Craver, W. L. (1965). Solitary amyloid tumor of the lung. A case report. Journal of Thoracic and $\vec{\circ}$ Cardiovascular Surgery, 49, 860.

Crosbie, W. A., Lewis, M. L., Ramsay, I. D., andw Doyle, D. (1972). Pulmonary amyloidosis with impaired gas transfer. Thorax, 27, 625.

Dahlin, D. C. (1949). Secondary amyloidosis. Annalsi of Internal Medicine, 31, 105.

Duke, M. (1959). Tumoral amyloidosis of the lungs Archives of Pathology, 67, 110.

Dyke, P. C., Demaray, M. J., Delavan, J. W., and Rasmussen, R. A. (1974). Pulmonary amyloidoma? American Journal of Clinical Pathology, 61 301.

Firestone, F. N. and Joison, J. (1966). Amyloidosis, a cause of primary tumors of the lung. Journate of Thoracic and Cardiovascular Surgery, 51, 292 가

Fors, B. and Ryden, L. (1964). Tumoral amyloidosis of lung. Acta Pathologica Microbiologico Scandinavica, 61, 1.

Glenner, G. G. (1972). The pathogenetic and thera peutic implications of the immunoglobulin origiro of amyloid fibrils. Human Pathology, 3, 157.

(1973). Immunoglobulin and amyloid fibrif proteins. British Journal of Haematology, $24 \frac{9}{3}$ 533.

—, Ein, D., and Terry, W. D. (1972). The ime munoglobulin origin of amyloid. Americai Journal of Medicine, 52, 141.

Gonzalez-Cueto, D. M., Rigoli, M., Gioseffi, L. M Lancelle, B., and Martinez, A. (1970). Diffuse pulmonary amyloidosis. American Journal of Medicine, 48, 668.

Hayes, W. T. and Bernhardt, H. (1969). Solitar amyloid mass of the lung. Cancer, 24, 820 .

Heiner, E. R. (1968). Primary amyloidosis of larynx Archives of Otolaryngology, 87, 413.

Isobe, T. and Osserman, E. F. (1974). Patterns o黑. amyloidosis and their association with plasmato cell dyscrasia, monoclonal immunoglobulins an $\$$ Bence-Jones proteins. New England Journal af Medicine, 290, 473.

Larsen, R. M. (1930). A pathological study of primary myocardial amyloidosis. Americał Journal of Pathology, 6, 147.

Lesser, A. (1877). Ein Fall von Enchondrom osteoides Mixtum der Lunge mit partieller Amyloidentartung. Archiv für pathologische Anatomie und Physiologie und für klinische Medizin, 69, 404.

McGurk, F. M. (1968). Case reports. Primar帝 bronchial amyloidosis. British Journal of
Radiology, 41, 795. 
Osserman, E. F., Takatsuki, K., and Tatal, N. (1964). Multiple myeloma. I. The pathogenesis of amyloidosis. Seminars of Hematology, 1, 3 .

Prowse, C. B. (1958). Amyloidosis of the lower respiratory tract. Thorax, 13, 308 .

Sappington, S. W., Davie, J. H., and Horneff, J. A (1942). Primary amyloidosis of the lungs. The Journal of Laboratory and Clinical Medicine, 27, 882.

Spencer, H. (1968). Pathology of the Lung, 2nd edition, pp. 689-694. Pergamon Press, Oxford.

Thomsen, O. F. (1968). Primary amyloidosis in lungs and heart. Acta Medica Scandinavica, 184, 125.

Weiss, L. (1960). Isolated multiple nodular pulmonary amyloidosis. American Journal of Clinical Pathology, 33, 318.
Whayne, T. F., Burkholder, P. M., and Becker, E. L. (1966). Primary amyloidosis. Journal of Chronic Diseases, 19, 1145.

Whitwell, F. (1953). Localized amyloid infiltrations of the lower respiratory tract. Thorax, 8, 309.

Zundel, W. E. and Prior, A. P. (1971). An amyloid lung. Thorax, 26, 357 .

Requests for reprints to: Dr. Siong-Chuan Lee, Department of Pathology, Indiana University School of Medicine, 1100 W. Michigan Street, Indianapolis, Indiana 46202, USA. 